\title{
Election 2008: where the parties stand - or not
}

Published at www.cmaj.ca on Sept. 18, 2008.

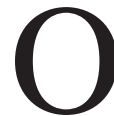
pinion polls consistently indicate that health care remains a main concern of Canadians, while health care expenditures now amount to $10.3 \%$ of Canada's gross domestic product, "the highest level in more than 30 years," according to the Canadian Institute for Health Information.

Health care spending is now annually in the neighbourhood of $\$ 150$ billion. In 2006, overall health spending increases outstripped inflation and population growth - for the tenth consecutive year.

In light of those staggering numbers, it would be reasonable to expect that health care would be a major campaign issue, yet the 5 political parties contending for Oct. 14, 2008, votes have been remarkably silent on health care issues in the early run-up to Canada's 40th general election.

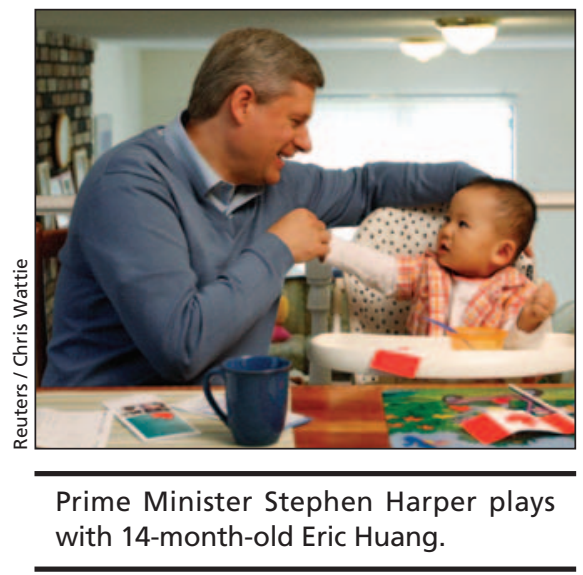

In the hope of drawing them out of their shells and elucidating their views on health issues, CMAJ submitted a 10question survey to each of the parties. In general, their responses reaffirmed the new truism of Canadian politics that campaign front-runners take no, or at best, few positions on issues, while parties trailing in the polls bend any, and all ears, with concrete proposals. But the rule of thumb was hardly inviolate as each of the parties, at times, responded with what could only be politely described as artful dodging. All responses can be viewed, verbatim, at www.cmaj.ca.

Nevertheless, there were discernable differences in party policies, as follows:
What are the priority areas in which your party would make new health investments?

The Conservatives favour the status quo, while the Liberals and New Democrats broadly affirmed support for publicly funded health care, timely access to care, public health and disease prevention, and a health human resources strategy. The New Democrats added long-term and home care to their list of priorities.

The Greens were by far the most prescriptive in response, saying they'd focus new investments on health promotion and preventative measures such as "removing chemicals that are known to pose a risk to human health, promoting greater physical activity thereby reducing obesity rates, and imposing a national junk food tax." They'd invest $1 \%$ (roughly $\$ 1.5$ billion) of Canada's health budget on promotion initiatives. The Bloc Québécois, meanwhile, reiterated their oft-stated position that health is a provincial jurisdiction and the federal government's only role is to write cheques to the provinces.

What specific measures should Canada take to resolve its current shortage of physicians?

None of the parties boldly stepped out in favour of a comprehensive pan-Canadian strategy for educating, recruiting, licensing and equipping doctors, as recommended by Task Force Two (CMAJ 2006;174[13]:1827-8).

But Liberals and New Democrats supported some form of fast-tracking the licensing of international medical graduates, although the Grits qualified that with the proviso, "if residency positions could be found and remedial training supplied."

The New Democrats and Greens would open federal coffers to expand quotas at medical schools, while the Liberals said more training spots require "closer collaboration among health, postsecondary education and labour market sectors." But they later vowed on the campaign trail to create a $\$ 420$ million "Doctors and Nurses Fund," while the New Democrats announced a $\$ 1$ billion, 5-year plan to

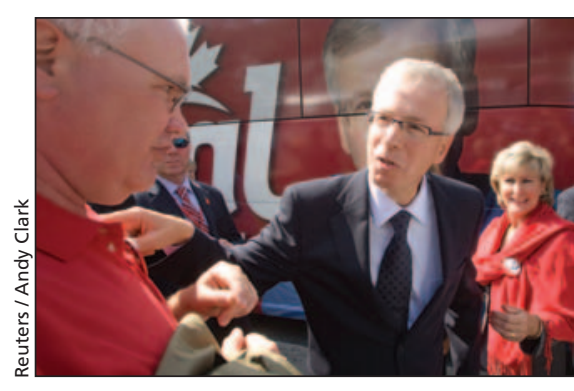

Liberal leader Stéphane Dion and candidate Roxanne Stanners on the trail.

boost medical school quotas by 1200 spots. The New Democrats and Greens endorsed student loan forgiveness for health care professionals who staff rural facilities and family practice clinics, while the Bloc and Conservatives said physician supply is a provincial matter.

Are current catastrophic drug cost programs adequate or should Canada move immediately to introduce a national pharmacare program?

The New Democrats and Greens championed national pharmacare, as well as national bulk buying of drugs and patent reforms to reduce the duration of protection now offered to pharmaceutical firms on new drugs. But the Greens qualified their stance by saying they'd first strike a commission to conduct a "cost-benefit" analysis. They would also launch a "public inquiry into the rising costs and overprescription of drugs.'

The Liberals and Conservatives, by contrast, ducked the issue, saying their preferred approach is catastrophic programming, as articulated in the National Pharmaceutical Strategy agreed to as part of the 2004 intergovernmental 10-Year Plan to Strengthen Health Care. The Liberals later announced on the campaign trail they'd invest $\$ 900$ million to that end. The Bloc said Ottawa has no role except transferring cash.

Should Canada adopt a national immunization program to prevent provincial and regional discrepancies in immunizing children?

The Liberals and New Democrats were careful not to step on provincial toes but indicated they were amenable to a national strategy. The Greens had no posi- 
tion, while the Conservatives and Bloc said immunization is not a federal matter.

Are you in favour of a progressive licensing regime for pharmaceuticals? If so, does the proposed progressive drug licensing regime have the teeth to protect consumers and ensure that regulatory authorities can obtain evidence from pharmaceutical firms during the post-market surveillance process?

The Conservatives lined up squarely behind their proposed revisions (CMAJ 2007;176[9]:1261-2), arguing that the regime "would tailor oversight to risk and thus strike an appropriate balance between the freedom of Canadians to choose, and the protection of their health." Industry laxity, they said, would be deterred by stiff $\$ 5$ million fines.

The Liberals and Greens completely dodged the issue, while the New Democrats offered the most nuanced response, saying they would strengthen adverse reaction reporting requirements, while also raising the bar for initial market authorization licences, including "stronger application of the precautionary principle." They would also fund a "drug effectiveness research network and the public reporting of clinical trials and their outcomes." The Bloc expressed concern about trading off a lower threshold for market authorization at the expense of Canadian's health.

Would you restore the public health ministry to full cabinet status?

The Liberals and New Democrats support the notion, while the Greens and Bloc side-stepped the issue. The Conservatives said public health is the responsibility of the Health Minister.

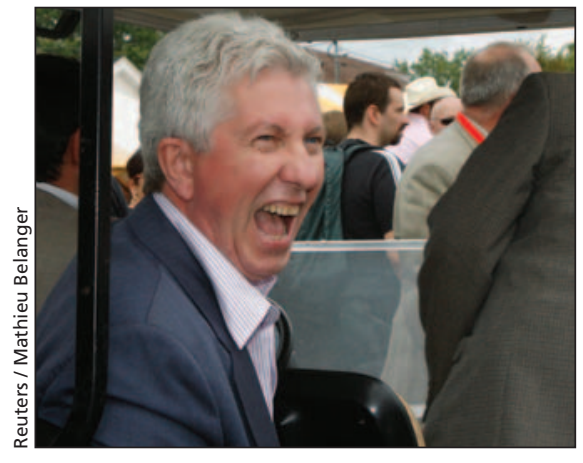

Bloc Québécois leader Gilles Duceppe campaigns in St-Tite, Quebec.

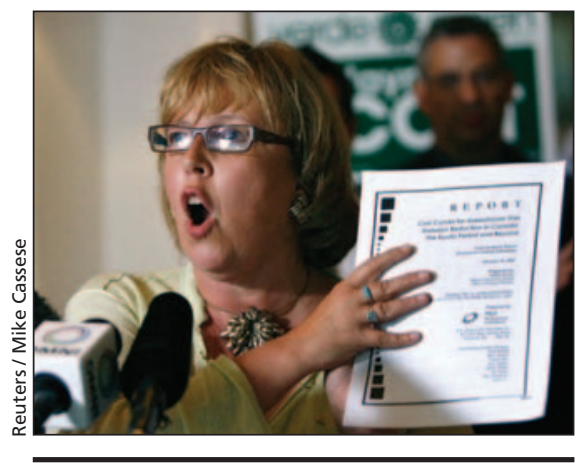

Green leader Elizabeth May holds up a report at a campaign stop in Ontario.

Should the PHAC be made an independent agency reporting directly to Parliament?

The New Democrats argued that giving the Public Health Agency of Canada independence and direct accountability to Parliament is the only way to ensure "timely responses," while the Liberals believe that reporting to a public health minister, rather than a health minister, is the solution. The Greens and Bloc took no position, while the Conservatives argued that PHAC "is already a separate agency within the Health Portfolio."

Given the demise of the MAPLEs reactor project, how would you ensure long-term supply of medical isotopes? The Liberals, New Democrats and Greens were extremely generous in their criticisms of the Conservative handling of the isotope crisis and subsequent cancellation of the the MAPLES reactor project (CMAJ 2008;178[13]:1648 and CMAJ 2008;178[7]:813-4). The Greens even called for a full public inquiry.

The New Democrats would seek an international contingency plan for uninterrupted isotope supply and vowed to develop a long-term strategy for domestic production. The Bloc plans to raise the matter in Parliament, while the Conservatives argued that all matters are firmly in hand: the National Research Universal reactor will be relicensed for 5 years in 2011, while consultations will subsequently be held on the question of long-term supply after 2016.

Should Canada have no-fault compensation for medical mishaps?

Only the Conservatives completely ruled out pursuit of no-fault compensation for medical mishaps (CMAJ 2008;179 [4]:309-11, CMAJ 2008;179[5]:407-9 and CMAJ 2008;179[6]:515-7). The Conservatives equated such compensation to "government auto insurance plans," and said that's the domain of the provinces. The Bloc concurred on jurisdictional grounds, while the Liberals and Greens said they'd be "open" to discussions on the issue. The New Democrats were the most amenable to pursuing a no-fault compensation scheme, saying that such a system "offers the best chance of achieving patient safety, patient compensation and physician accountability while protecting physicians financially."

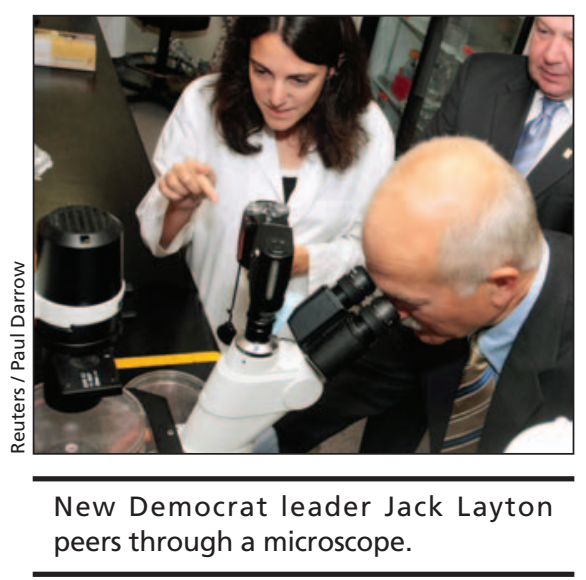

Since the new millennium, what is the single largest failure of a health minister in Canada?

The political spin was often dizzying in response. The Liberals tagged the Conservatives' handling of the listeriosis outbreak and revisions to the food safety regulatory regime (see page 755), as a betrayal of public trust. The New Democrats said all past health ministers were equally culpable for the current physician shortage.

The Conservatives said predecessor Liberal governments were indifferent to wait times, while "history will undoubtedly judge the tragic refusal to compensate Hepatitis $\mathrm{C}$ victims for their pain and suffering as one of the greatest failures of any Canadian health minister." The Greens declined to "point fingers," while the Bloc offered no comment. -Wayne Kondro, CMAJ

DOI:10.1503/cmaj.081460 